\title{
Broken chair und Engel
}

\author{
Vom 30. April bis 7. Juni 2011 fand in der Galerie zur Hammermühle* in Ibach/ \\ Schwyz zum vierten Mal eine Bilderausstellung der Vereinigung «Kunstausstel- \\ lung der Schweizer Ärzte / Salon des Médecins Suisses»** statt. Seit Beginn geht \\ ein Teil des Erlöses dieser Ausstellungen an die Organisation «Welt ohne Minen» \\ (WOM).***
}

David Künzler

www.hanni-mirer.ch ** www.aerzte-kunst.ch *** www.wom.ch
In seiner Funktion als Präsident der Kunstausstellung versuchte der Schreibende, in der Eröffnungsansprache einen Bogen zu schlagen zwischen der Schönheit vollendeter Kunstwerke und der Heimtücke verborgener Waffen, die in herzloser, unmenschlicher Art das Gegenteil bewirken, nämlich Hässlichkeit, Verletzungen, Unvollständigkeit.

«Minen sind wohl die perfideste Waffe, die man sich denken kann, da sie ganz im Versteckten plaziert werden, so dass nach einiger Zeit oft nicht einmal mehr diejenigen, die sie gelegt haben, wissen oder wissen wollen, wo sie sind. So bleiben sie millionenfach liegen und verletzen und töten noch Jahre später unschuldige Zivilisten, allen voran Arbeiter auf Land

\section{Abbildung 1}

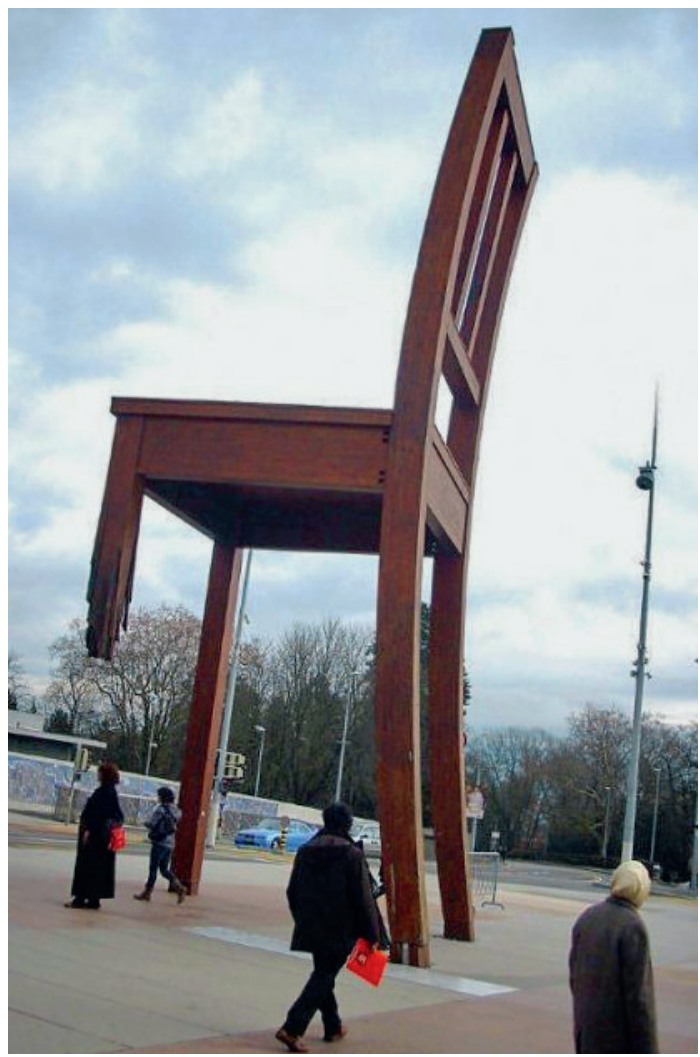

und Feld - und Kinder.» Das Typische an den Minen ist, dass man sie nicht sieht, dass sie nur dann zerstörerisch und tödlich sind, wenn man auf sie tritt und dass die Gesellschaft wenig darüber weiss oder nichts wissen will. Es wird wohl über Minen berichtet, aber nur versteckt in kleinen Artikeln, so dass man sehr aufmerksam sein muss, um etwas darüber zu erfahren.

\section{Polarität in der Kunst}

Vor einigen Monaten sah ich in Genf einen Riesenstuhl (Abb. 1), aber erst beim zweiten Hinschauen bemerkte ich, dass ein Bein abgebrochen ist (Abb. 2). Das Werk soll auf die Unmenschlichkeit der Minen

Abbildung 2

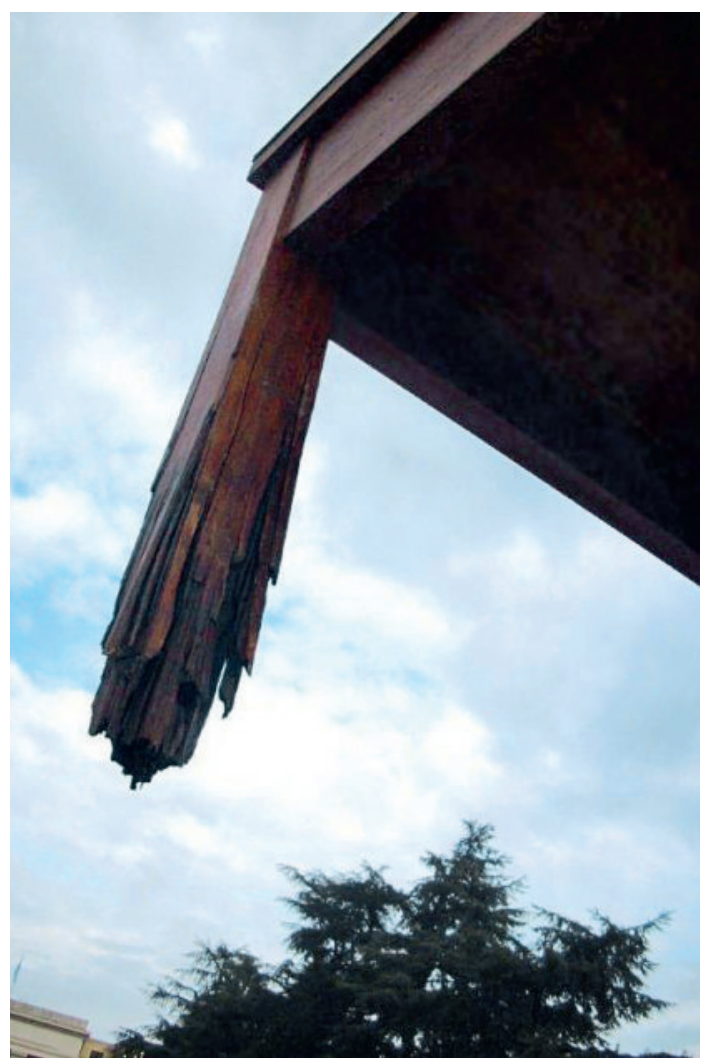




\section{Abbildung 3}

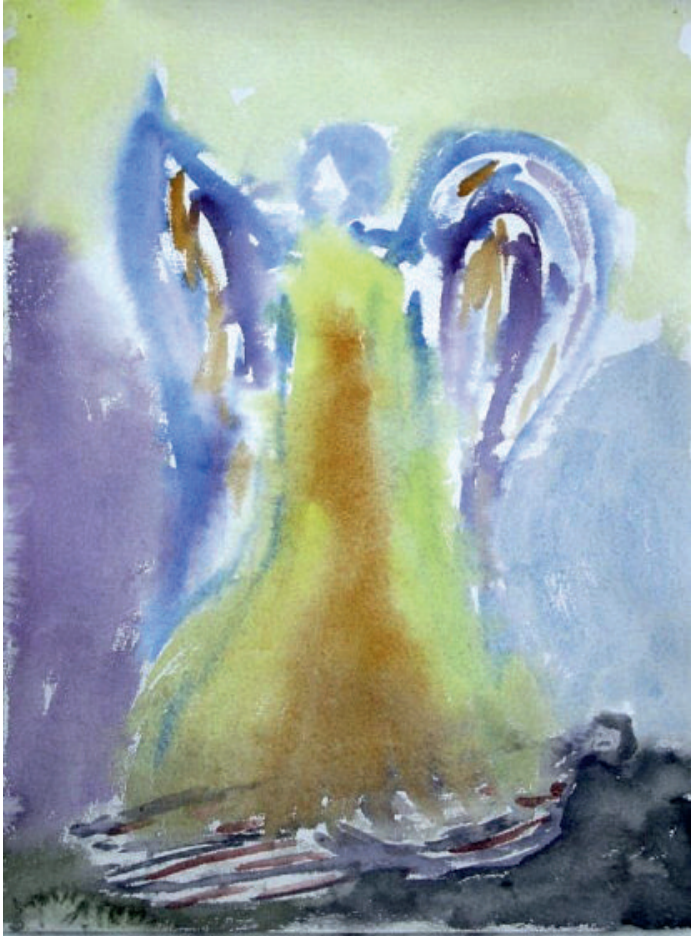

aufmerksam machen. Dem möchte ich im Sinne «Schönheit wird die Welt erlösen» (Dostojewski) das Bild eines von mir gemalten Engels (Abb. 3) gegenüberstellen.

Auch dieses Mal ist in der Ausstellung sehr viel Schönes ausgestellt. Versuchen Sie doch, bei der Betrachtung von Kunstwerken diese Schönheit zu sehen und damit irgendwie das Böse, das versteckt existiert, zu entschärfen - für sich selber und für die Welt.

\section{Abbildung 5}

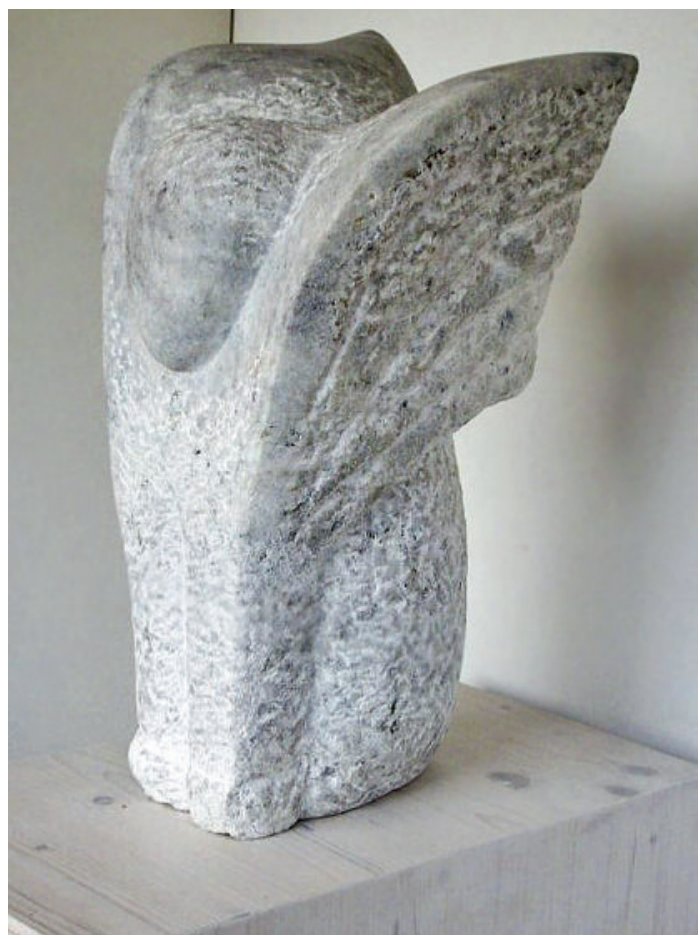

\section{Abbildung 4}

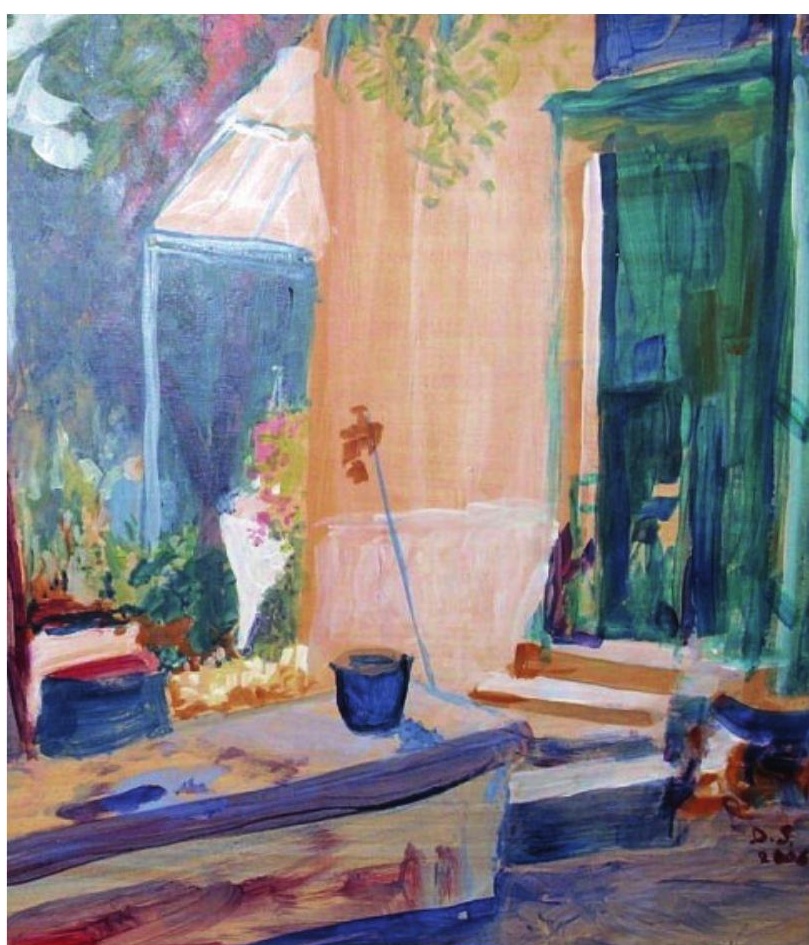

Abb. 1: Mahnmal «Der zerbrochene Stuhl» für die Opfer von Landminen von Daniel Berset vor dem Sitz der Vereinten Nationen, UNO, Genf.

Abb. 2: «Der zerbrochene Stuhl», Detail.

Abb. 3: David Künzler: Engel.

Abb. 4: Dieter Schwenk: Südfrankreich (Ausschnitt, Acryl).

Abb. 5: Regina Altdorfer: Sphinx (Marmor).

Abb. 6: Franziska Burkhardt: Spaziergang (Radierung).

\section{Abbildung 6}

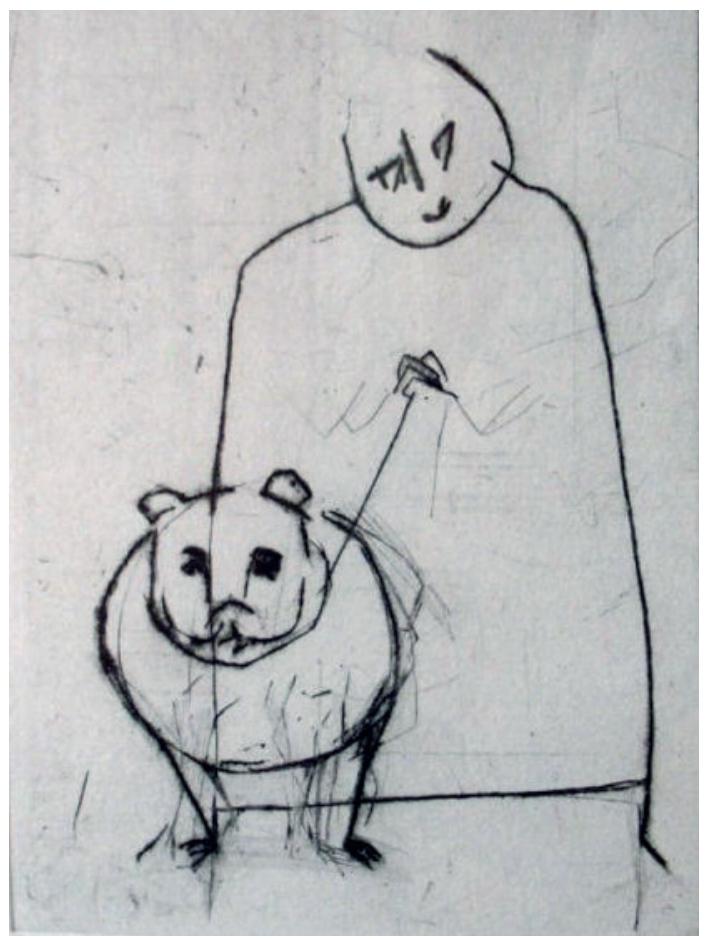

